\title{
LARGE SCALE STRUCTURES OF THE UNIVERSE
}

Edited by JEAN AUDOUZE, MARIE-CHRISTINE PELLETAN and ALEX SZALAY
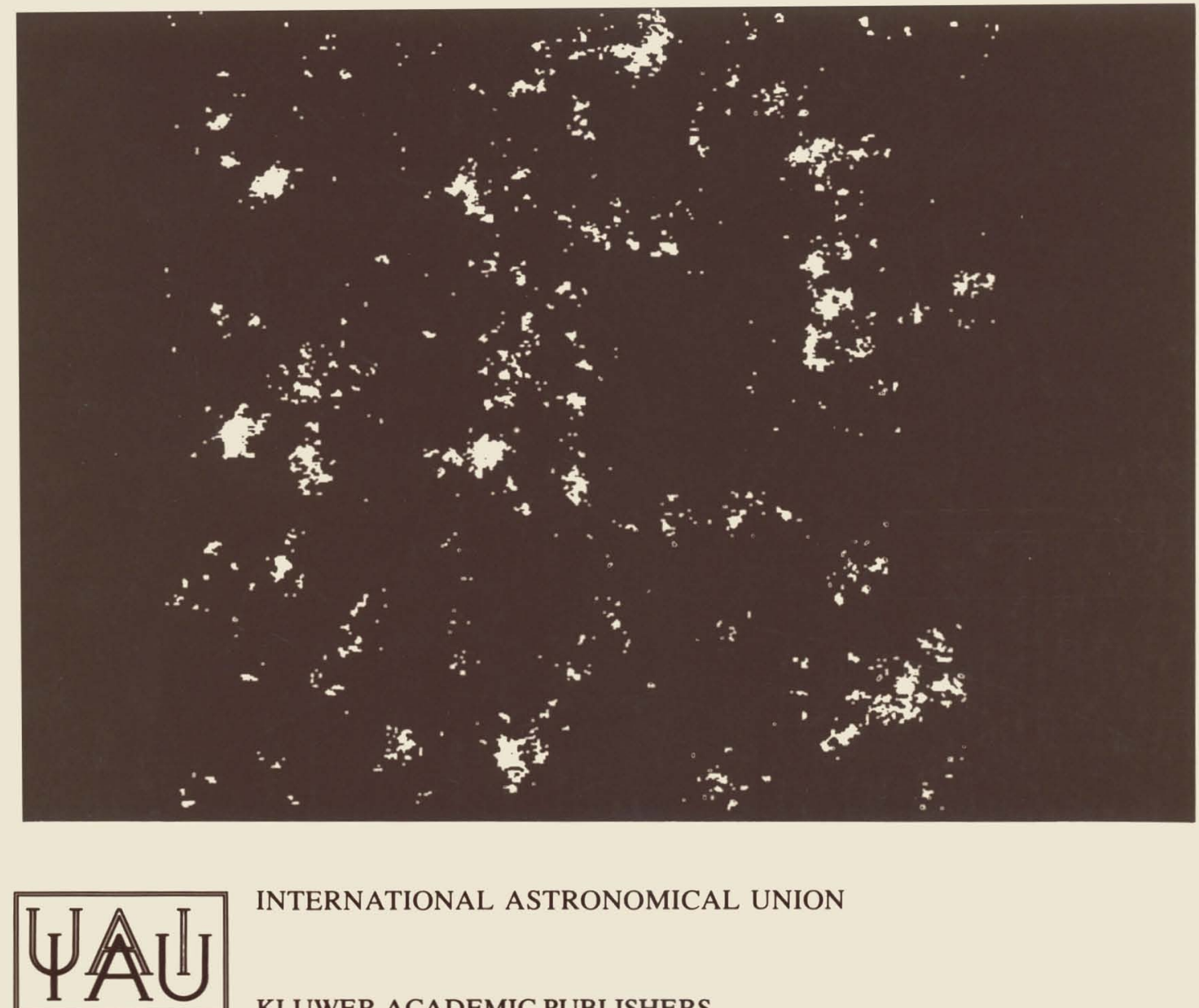

INTERNATIONAL ASTRONOMICAL UNION

KLUWER ACADEMIC PUBLISHERS 
LARGE SCALE STRUCTURES OF THE UNIVERSE 


\section{LARGE SCALE STRUCTURES \\ OF THE UNIVERSE}

PROCEEDINGS OF THE 130TH SYMPOSIUM OF THE INTERNATIONAL ASTRONOMICAL UNION, DEDICATED TO THE MEMORY OF MARC A. AARONSON (1950-1987), HELD IN BALATONFURED, HUNGARY, JUNE 15-20, 1987

\section{EDITED BY}

\section{JEAN AUDOUZE}

Institut d'Astrophysique du CNRS, Paris, France

MARIE-CHRISTINE PELLETAN

Institut d'Astrophysique du CNRS, Paris, France

and

\section{ALEX SZALAY}

Department of Atomic Physics, The Eötvös University, Budapest, Hungary

\section{KLUWER ACADEMIC PUBLISHERS}

DORDRECHT / BOSTON / LONDON

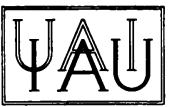


Library of Congress Cataloging in Publication Data

International Astronomical Union. Symposium (130th :

1987 : Balatonflired, Hungary)

Large scale structures of the universe.

Includes indexes.

1. Cosmology--Congresses. 2. Galaxies--Congresses.

3. Radio astronomy--Congresses. 4. Infrared astronomy--

Congresses. 5. Aaronson, Marc A., 1950-1987.

I. Aaronson, Marc A., 1950-1987. II. Audouze, Jean.

III. Pelletan, Marie-Christine. IV. Szalay, Sándor,

1909- . V. Title.

QB980.I57 $1987 \quad 523.1 \quad 88-6821$

ISBN 90-277-2742-2

ISBN 90-277-2744-9 (pbk.)

\title{
Published on behalf of \\ the International Astronomical Union \\ by
}

Kluwer Academic Publishers, P.O. Box 17, 3300 AA Dordrecht, The Netherlands.

Kluwer Academic Publishers incorporates

the publishing programmes of

D. Reidel, Martinus Nijhoff, Dr W. Junk and MTP Press.

Sold and distributed in the U.S.A. and Canada by Kluwer Academic Publishers,

101 Philip Drive, Norwell, MA 02061, U.S.A.

In all other countries, sold and distributed

by Kluwer Academic Publishers Group,

P.O. Box 322, 3300 AH Dordrecht, The Netherlands.

\author{
All Rights Reserved \\ (C) 1988 by the International Astronomical Union
}

No part of the material protected by this copyright notice may be reproduced or utilized in any form or by any means, electronic or mechanical including photocopying, recording or by any information storage and retrieval system, without written permission from the publisher.

Printed in The Netherlands 


\section{TABLE OF CONTENTS}

ORGANIZING COMMITTEES

FRONTISPIECE

vi

PREFACE

xxi

PROGRAMME OF THE SYMPOSIUM

$\mathbf{x x v}$

LIST OF PARTICIPANTS

xxix

OPENING ADDRESS

Ya. B. Zeldovich $\dagger$

RECENT MEASUREMENTS OF THE COSMIC MICROWAVE RADIATION

D.T. Wilkinson

THE ANISOTROPY IN THE DISTRIBUTION OF EXTRAGALACTIC INFRARED SOURCES AND BACKGROUND

P. de Bernardis, R. Fabbri, S. Masi, F. Melchiorri, B. Olivo, W. Pecorella

THE IZANA COSMIC MICROWAVE BACKGROUND FLUCTUATIONS EXPERIMENT : A PROGRESS REPORT

R.A. Watson, R. Rebolo, R.D. Davies, A.N. Lasenby, J.E. Beckman

THE ANISOTROPY OF THE MICROWAVE BACKGROUND : SPACE EXPERIMENT RELICT

I.A. Strukov, D.P. Skulachev, A.A. Klypin

$\dagger$ deceased on $12 / 2 / 87$ 
SUMMARY OF THE USSR GROUND BASED OBSERVATIONS OF THE 3 K ANISOTROPY

Y.N. Parijskij

AN UPPER LIMIT TO THE INTRINSIC ANISOTROPY OF THE MICROWAVE BACKGROUND RADIATION ON A SCALE OF 7 ARC MINUTES

A.C.S. Readhead, C.R. Lawrence, S.T. Myers, W.L.W. Sargent

ANISOTROPY OF THE MICROWAVE BACKGROUND AND

BIASED GALAXY FORMATION

N. Kaiser

INFLATION AND THE LARGE SCALE STRUCTURE OF THE UNIVERSE

L.A. Kofman, A.D. Linde, V.F. Mukhanov

SOME CRITICAL REMARKS ON THE INFLATIONARY UNIVERSE CONCEPT

G. Börner

EVOLUTION OF INHOMOGENEITIES IN THE INFLATIONARY UNIVERSE - NO HAIR THEOREM OR MULTI-PRODUCTION OF UNIVERSES ?

K. Sato

COSMIC STRUCTURES FORMATION IN THE MULTICOMPONENT UNIVERSE : NEW TESTS

V.N. Lukash

QUANTITATIVE PREDICTIONS OF CMB ANISOTROPIES AND DISTORTIONS

J.R. Bond

THE Cfa REDSHIFT SURVEY

J.P. Huchra, M.J. Geller, V. de Lapparent, R. Burg

RESULTS OF THE PISCES-PERSEUS HI REDSHIFT SURVEY

R. Giovanelli, M.P. Haynes

THE LARGE SCALE DISTRIBUTION OF GALAXIES IN THE SOUTHERN HEMISPHERE

L.N. Da Costa, P.S. Pellegrini

THE EDINBURGH-DURHAM SOUTHERN GALAXY CATALOGUE

C.A. Collins, N. Heydon-Dumbleton, H.T. MacGillivray, T. Shanks

POSSIBLE INHOMOGENEITIES IN THE UNIVERSE ON SCALES 100-300 MPC FROM OBSERVATIONS WITH THE 6-METER TELESCOPE

A.I. Kopylov, D.Y. Kuznetsov, T.S. Fetisova, V.F. Shvartsman

$\ddagger$ deceased on $8 / 25 / 87$ 
A CUT OF LARGE-SCALE STRUCTURE ACROSS THE COMA SUPERCLUSTER

I.D. Karachentsev, A.I. Kopylov

THE APM GALAXY SURVEY

S.J. Maddox, G. Efstathiou, J. Loveday

A FIT OF THE ANGULAR 3-POINT FUNCTION AND BIASED

GALAXY FORMATION

S.A. Bonometto, F. Lucchin, S. Matarrese

161

CONSTRAINTS ON THE BIASING OF DENSITY FLUCTUATIONS

A.S. Szalay

163

ELLIPTICAL GALAXIES AND LARGE SCALE VELOCITY FLOWS

S.M. Faber, D. Burstein, R.L. Davies, A. Dressler, D. Lynden-Bell,

R. Terlevich, G. Wegner

SPIRAL GALAXIES, ELLIPTICAL GALAXIES AND THE LARGE-

SCALE VELOCITY FIELD WITHIN $3500 \mathrm{KM} / \mathrm{S}$

OF THE LOCAL GROUP

D. Burstein, R.L. Davies, A. Dressler, S.M. Faber, D. Lynden-Bell,

R. Terlevich, G. Wegner

177

COHERENT LARGE SCALE MOTIONS FROM A NEW SAMPLE OF

SPIRAL GALAXIES

V.C. Rubin

181

LARGE PECULIAR VELOCITIES IN THE HYDRA CENTAURUS SUPERCLUSTER

M. Aaronson, G.D. Bothun, K.G. Budge, J.A. Dawe, R.J. Dickens,

P.J. Hall, J.R. Lucey, J.R. Mould, J.D. Murray, R.A. Schommer,

A.E. Wright

185

A REDSHIFT SURVEY OF IRAS GALAXIES

M.A. Strauss, M. Davis

191

THE HIGH ENERGY X-RAY BACKGROUND AND LIMITS ON

LARGE SCALE STRUCTURE

A. Meszaros, P. Meszaros

A VLA SEARCH FOR COSMOLOGICAL HI

L. Noreau, E. Hardy

A WSRT SEARCH FOR HI AT $\mathrm{Z}=3.35$

A.G. De Bruyn, M.H. Wieringa, P. Katgert, R. Sancisi

211

GALAXIES, CLUSTERS AND FLUCTUATIONS

R. Schaeffer 
xii

OBSERVATIONS OF FAINT FIELD GALAXIES

D.C. Koo

221

SUPERCLUSTERING AND MOTION OF GALAXY CLUSTERS

N.A. Bahcall

229

THE ORIENTATION OF GALAXIES IN SUPERCLUSTERS

P. Flin

239

THE PISCES-CETUS SUPERCLUSTER COMPLEX

R.B. Tully

243

SUPERCLUSTERING : THEORY VERSUS OBSERVATIONS

J. Einasto, M. Einasto, E. Saar, B.J.T. Jones, V.J. Martinez

245

TWO QUESTIONS ABOUT THE LARGE SCALE

DISTRIBUTION OF GALAXIES

M.J. Geller

255

N-BODY SIMULATIONS OF GALAXY FORMATION

C.S. Frenk

259

THEORIES OF LARGE SCALE STRUCTURE

S.F. Shandarin

273

COSMIC STRINGS AND GALAXY FORMATION

N. Turok

281

IS COSMIC STRING DOMINATION OF THE UNIVERSE AVOIDABLE?

F.R. Bouchet, D.P. Bennett

289

LARGE SCALE STRUCTURE OF THE UNIVERSE IN UNSTABLE

DARK MATTER MODELS

A.G. Doroshkevich, A.A. Klypin, M.U. Khlopov

293

FORMATION OF DISK GALAXIES

K.C. Freeman

301

OBSERVATIONAL EVIDENCE FOR SPECTRAL EVOLUTION OF CLUSTER GALAXIES

A. Dressler, J.E. Gunn

311

EXPLOSIVE ORIGINS OF LARGE-SCALE STRUCTURES

J.P. Ostriker

GALAXY FORMATION AND EVOLUTION

G. Bruzual

QUASAR ABSORPTION LINES : EVOLUTION AND CLUSTERING W.L.W. Sargent 
GALAXIES GIVING RISE TO MGII ABSORPTION SYSTEMS IN QUASAR SPECTRA

J. Bergeron

QUASAR CLUSTERING AND THE EVOLUTION OF STRUCTURE P.A. Shaver

OBSERVATION OF GALAXY AND QSO CLUSTERING

T. Shanks, D. Hale-Sutton, B.J. Boyle

THE DISTRIBUTION OF FAINT RADIO SOURCES AT 6CM

K.I. Kellermann, E.B. Fomalont

DISCUSSION SESSION : GALAXY FORMATION AND QUASI STELLAR OBJECTS

J.E. Gunn, J. Silk

DYNAMICAL EVIDENCE FOR DARK MATTER IN INDIVIDUAL DISK GALAXIES

E. Athanassoula, A. Bosma

DARK MATTER IN SINGLE AND DOUBLE GALAXIES

T.S. Van Albada

401

DARK MATTER IN DWARF GALAXIES

M. Aaronson, E.W. Olszewski

DISSIPATION AND FORMATION OF GALACTIC HALOS

G.R. Blumenthal

GALAXY FORMATION AND LARGE SCALE STRUCTURES IN

A TWO-COMPONENT DARK MATTER SCENARIO

M. Umemura

DARK MATTER AND COOLING FLOWS

B.J. Carr, K.M. Ashman

429

BIASED GALAXY FORMATION AND DARK MATTER M.J. Rees

GRAVITATIONAL LENSES

B.J. Burke

IS THE GIANT LUMINOUS ARC IN A370 A GRAVITATIONAL

LENSING EFFECT ?

Y. Mellier

GIANT LUMINOUS ARCS IN CLUSTERS OF GALAXIES

R. Lynds, V. Petrosian 
COSMOLOGICAL IMPLICATIONS OF THE FIFTH FORCE

Y. Fujii

DISCUSSION PANEL

R. Cowsik, B. Mandelbrot, J. Primack, E.E. Salpeter, H. Sato,

N. Vittorio

SUMMARY

P.J.E. Peebles

495

APPENDIX 1 POSTER PAPERS

DISTORTION OF COSMIC MICROWAVE BACKGROUND RADIATION AND DECAY OF WEAKLY INTERACTING PARTICLES

K. Sato, M. Kawasaki

DIPOLE ANISOTROPY IN THE LICK GALAXY CATALOGUE

M. Plionis

TRINITY RELATIONS IN THE UNIVERSE

Y. Suto, R. Juskiewicz, J. Silk

512

MICROWAVE BACKGROUND ANISOTROPIES IN A BARYON

DOMINATED UNIVERSE

Y. Suto, N. Gouda, M. Sasaki

PRIMORDIAL DENSITY PERTURBATIONS IN TEPID INFLATION

B. Lukacs, G. Paal

VACUUM POLARIZATION AND SCALAR FIELD EFFECTS

IN THE EARLY UNIVERSE

S. Gottlober, V. Muller, H.J. Haubold, J.P. Mucket

SELF SIMILAR COSMOLOGICAL MODELS WITH A COSMICAL CONSTANT

R.M. Green, D. Alexander

ON THE OBSERVATIONAL DISCRIMINATION OF FRIEDMANN -

LEMAITRE MODELS

Y. Chu, J. Hoell, H.J. Blome, W. Priester

SOLITONS IN NEWTONIAN GRAVITY AND NON LINEAR PANCAKE EVOLUTION

G. Götz

THE CENTER FOR ASTROPHYSICS REDSHIFT SURVEY :

LUMINOSITY FUNCTION AND TWO-POINT CORRELATION

FUNCTION

V. De Lapparent, M.J. Geller, J.P. Huchra 
THE CENTAURUS-PAVO SUPERCLUSTER

A.P. Fairall

GALAXY CLUSTERS IN THE APM SURVEY

S.J. Maddox

521

HYDRA CENTAURUS : A REDSHIFT SURVEY

G. Chincarini, L. Da Costa, A.P. Fairall, P. Pellegrini, G. Vettolani, C. Willmer

522

A REDSHIFT SURVEY IN THE DIRECTION OF A VOID NEAR

THE PISCES-CETUS SUPERCLUSTER

J.P. Brodie, J. Willick, S. Bowyer, J.O. Burns

523

TRACING LARGE SCALE STRUCTURE WITH GALAXY

OBJECTIVE-PRISM SPECTRA

Q.A. Parker, H.T. MacGillivray, S.M. Beard

MRSP - THE MUENSTER REDSHIFT PROJECT

P. Schuecker, H. Hortsmann, W. Seitter

526

ANGULAR CORRELATIONS OF FAINT (B < 24) GALAXIES

L.R. Jones, T. Shanks, R. Fong

528

RESULTS FROM THE 1000 GALAXY SAMPLE : THE CORRELATION

FUNCTION AT $Z=0.75$ AND THE EVOLUTION OF THE

CHARACTERISTIC LUMINOSITY

E.D. Loh

529

GALAXY GROUPS : MORPHOLOGICAL SEGREGATION BETWEEN

SPIRALS

G. Giuricin, F. Mardirossian, M. Mezzetti, A. Pisani, M. Ramella

A SEARCH FOR A VESTIGIAL OBJECT IN THE CENTRE

OF A COSMIC VOID

G.F.R. Ellis, A.P. Fairall, A. Maurellis, D.R. Matravers

CORONA BOREALIS SUPERCLUSTER

M. Kalinkov, I. Kuneva, A. Kopylov

SPACE DISTRIBUTION OF THE RICHEST ABELL CLUSTERS OF GALAXIES

M. Kalinkov, I. Kuneva

A NEW CATALOG OF SUPERCLUSTERS OF GALAXIES

M. Kalinkov, I. Kuneva

IS COMA A YOUNG AGGREGATE OF OLD SUBCLUSTERS

Y. Mellier, G. Mathez, A. Mazure 
ABELL CLUSTERS AS TRACERS OF LARGE SCALE STRUCTURE :

ALIGNMENTS AND SUBSTRUCTURE

G. Rhee, P. Katgert

SUBSTRUCTURE IN RICH CLUSTERS

R. Webster, M. Fitchett, P. Hewett, M. Colless

THE 3-D DISTRIBUTION OF ABELL CLUSTERS

W. Sutherland

THE LARGE SCALE STRUCTURE OF THE X-RAY UNIVERSE

X. Barcons, A.C. Fabian

A POSSIBLE CONNECTION BETWEEN THE DIFFUSE X-RAY

BACKGROUND AND LARGE SCALE STRUCTURES IN THE UNIVERSE

R.A. Daly

SPACE DISTRIBUTION OF X-RAY CLUSTERS OF GALAXIES

A. Cavaliere, S. Colafrancesco

X-RAY SELECTED CLUSTERS OF GALAXIES

I. Gioia, T. Maccacaro, S.L. Morris, R.E. Schild, J.T. Stocke, A. Wolter

LARGE SCALE STRUCTURE AMONG ABELL CLUSTERS

AND COMPARISONS TO MODELS

D.J. Batuski, J.O. Burns, A. Melott

ACQUISITION OF ANGULAR MOMENTUM IN THE PROTOGALACTIC PHASES

R. Caimmi, E. Andreani, L. Secco

544

MERGER RATES IN SIMULATED AND OBSERVED GROUPS

OF GALAXIES

G.A. Mamon

545

ALIGNMENT OF CLUSTERS WITH BRIGHTEST MEMBER GALAXIES

G.S. Tucker, J.B. Peterson

ALIGNMENT EFFECTS OF BRIGHTEST CLUSTER GALAXIES

D.G. Lambas, P.J.E. Peebles, E.J. Groth

STATISTICS OF GALAXY ORIENTATIONS : MORPHOLOGY

AND THE LARGE SCALE STRUCTURE

D.G. Lambas, E.J. Groth, P.J.E. Peebles

CLUSTER CORRELATIONS FOR SCALE FREE SPECTRA

J.L. Sanz, E. Martinez-Gonzalez

THE CROSS-CORRELATION OF ABELL CLUSTERS WITH

THE LICK GALAXY COUNTS

P.B. Lilje, G. Efstathiou 
COSMOLOGICAL STREAMING VELOCITIES AND LARGE-SCALE DENSITY MAXIMA

J.A. Peacock, S.L. Lumsden, A.F. Heavens

ANGULAR MOMENTUM GROWTH AROUND LOCAL DENSITY MAXIMA

A.F. Heavens, J.A. Peacock

THE FRACTAL TURBULENCE AND THE ORIGIN OF LARGE

SCALE STRUCTURE

Y.Z. Liu, Z.G. Deng

553

CROSS CORRELATION ANALYSIS OF GALAXIES WITH DIFFERENT

LUMINOSITY

X.Y. Xia, Z.G. Deng, Y.Z. Liu

FRACTAL DIMENSION IN THE LARGE SCALE DISTRIBUTION

OF GALAXIES

Z.G. Deng, Z. Wen, Y.Z. Liu

THEORETICAL MODELS FOR THE GALAXY ANGULAR

CORRELATION FUNCTION

H.M.P. Couchman, J.R. Bond

THE ADVENT OF COSMOLOGICAL GAS DYNAMIC SIMULATIONS

A.E. Evrard

ON THE GOODNESS OF DIFFERENT MASS ESTIMATORS

FROM N-BODY SIMULATIONS

J. Perea, A. del Olmo, M. Moles

FROM 2-D TO 3-D BY MAXIMUM ENTROPY METHOD

O. Lahav, D. Lynden-Bell, S.F. Gull

GALAXY FORMATION WITH HOT DARK MATTER AND COSMIC STRINGS

R.H. Brandenberger

COSMIC STRINGS WAKES AND LARGE SCALE STRUCTURE

A. Stebbins, S. Veeraraghavan, R. Brandenberger, J. Silk, N. Turok

IMPLEMENTATION OF A TREE CODE FOR COSMOLOGY

F.R. Bouchet, L. Hernquist

THE SPACETIME SURROUNDING SUPERCONDUCTING COSMIC STRINGS

T.M. Helliwell, D.A. Konkowski

EFFECTS OF QUANTUM FIELDS OUTSIDE COSMIC STRINGS

D.A. Konkowski, T.M. Helliwell 
xviii

COSMIC STRINGS AS A CANDIDATE FOR DARK MATTER.

ASTROPHYSICAL FORMULAE

M.P. Dabrowski, J. Stelmach

566

ROTATION PROFILE OF A STRING-SEEDED HALO

W.H. Zurek, P.J. Quinn

LARGE SCALE STREAMING IN THE WAKE OF A LOOP OF COSMIC STRING

W.H. Zurek, Y. Hoffman

ARE VOIDS PRESENT IN THE LYMAN-ALPHA FOREST ?

A.P.S. Crotts

569

DOES A PERIODICITY EXIST IN THE REDSHIFT DISTRIBUTION

OF QUASARS' LYMAN-ALPHA ABSORPTION LINES?

X.F. Zhu, Y.Q. Chu

570

ON THE INTERPRETATION OF QSO ABSORPTION LINES

V. Muller, J.P. Mucket, S. Gottlober, H.J. Haubold

EVOLUTION OF QUASAR CLUSTERING

A. Iovino, P. Shaver

572

THE INTERACTION OF THE QUASAR PKS 0812+02 WITH THE

SURROUNDING CLUSTER OF GALAXIES

L. Guzzo, I.J. Danziger, S. Cristiani, P.A. Shaver

573

QUASAR CLUSTERING AT INTERMEDIATE REDSHIFTS

M. Drinkwater

THE ENVIRONMENTS OF OPTICALLY-SELECTED QSOs

B.J. Boyle, T. Shanks, H. Yee

576

PROPERTIES OF GALAXIES AND GALAXY CLUSTERS ASSOCIATED WITH QUASARS

K.C. Yee

QSO SURFACE DENSITY AT FAINT LIGHT LEVELS

V.L. Afanasiev, S.N. Dodonov, T. Boller, H. Lorenz, V.Y. Terebizh

RADIO GALAXIES AS LARGE-SCALE COSMOLOGICAL PROBES

J.A. Peacock, L. Miller, C.A. Collins, D. Nicholson, S.J. Lilly

SPATIAL CORRELATION FUNCTIONS OF BRIGHT RADIO-GALAXIES

Y.Y. Zhou, Y.P. Jing

SOME REMARKS ON OBSERVATIONAL PROBLEMS FOR DISK-

GALAXY EVOLUTION

M. Sanromà, E. Salvador-Solé, J.M. Solanes 
THE GENERAL GALAXY LUMINOSITY FUNCTION

E. Martinez-Gonzalez, J.L. Sanz

EXPLOSIONS IN PANCAKE MODELS OF GALAXY FORMATION

J.G. More, A.F. Heavens, M.J. Wilson, A.S. Trew

THE ROTATION OF SPIRAL GALAXIES : INFALL MODEL VS OBSERVATIONS

R.A. Flores

DARK MATTER AROUND THE LOCAL GROUP ?

E. Giraud

OBSERVED DISTORTIONS (FROM LINEARITY) OF THE HUBBLE

FLOW AND BIAS IN THE DATA

E. Giraud

ON DYNAMICAL ANALYSIS OF HYDROSTATIC SELF-

GRAVITATING SPHERE : APPLICATION TO GALAXY CLUSTERS

R. Sadat, D. Gerbal

STRUCTURE OF GALAXIES EMBEDDED IN CLOUDS OF DARK MATTER

R. Cowsik

GLOBULAR CLUSTERS AND DARK CLUSTERS

K.M. Ashman

THE COUPLING OF MODES AND THE FORMATION OF POPULATION III OBJECTS

J.P. Mucket, H.J. Haubold, S. Gottlober, V. Muller

ON THE POSSIBILITY OF A HIGHER BARYONIC CONTRIBUTION TO DARK MATTER

R. Dominguez-Tenreiro, G. Yepes

PATH INTEGRAL METHODS FOR PRIMORDIAL DENSITY PERTURBATIONS

E. Bertschinger, J.M. Gelb

DO PREGALACTIC SHOCKS TRIGGER OR PREVENT GALAXY FORMATION

J. Madsen

ANTIBIASED GALAXY FORMATION IN THE PANCAKE SCENARIO

A. Dekel, E. Braun, P. Shapiro

NON-LINEAR EVOLUTION OF ACOUSTIC WAVES IN DUST INTERACTING WITH DARK MATTER IN NEWTONIAN COSMOLOGY : BIASING, VOIDS AND THE KADOMTSEV-PETVIASHVILI EQUATION 
GRAVITATIONAL LENSING : COSMOLOGICAL IMPLICATIONS

L. Nottale

GIANT ARCS-SPHERICAL SHELLS ?

A. Dekel, E. Braun

MORPHOLOGY OF HIGH REDSHIFT 3CR GALAXIES ( $>1)$, FROM HIGH SPATIAL RESOLUTION IMAGING

O. Le Fèvre, F. Hammer, L. Nottale, A. Mazure

GRAVITATIONAL LENSING AND COSMIC STRINGS

R. Webster, P. Hewett

600

ON THE POSSIBILITIES OF DETECTING DARK MATTER BY

THE GRAVITATIONAL LENS EFFECT

R. Kayser

601

IT IS NOT EASY TO REPLACE NEWTONIAN GRAVITATIONAL THEORY

D. Gerbal, H. Sirousse-Zia

602

\section{APPENDIX 2}

THE BALATONFÜRED ALPHABET OF COSMOLOGY

V. Rich

605

INDEX OF AUTHORS $\quad 609$

INDEX OF SUBJECTS 